\title{
Corrigendum: Dense array EEG source estimation in neocortical epilepsy
}

\author{
Madoka Yamazaki ${ }^{1,2}{ }^{*}$, Don M. Tucker ${ }^{3,4}$, Marie Terrill ${ }^{4}$, Ayataka Fujimoto ${ }^{2}$ and Takamichi Yamamoto ${ }^{2}$ \\ 1 Department of Health Science, Daito Bunka University, Saitama, Japan \\ 2 Comprehensive Epilepsy Center, Seirei Hamamatsu General Hospital, Shizuoka, Japan \\ ${ }^{3}$ Department of Psychology, University of Oregon, Eugene, OR, USA \\ ${ }^{4}$ Electrical Geodesics, Inc., Eugene, OR, USA \\ ${ }^{*}$ Correspondence: madokaymzk@gmail.com \\ Edited by: \\ Jeremy Daniel Slater, University of Texas Medical School, USA
}

\section{A commentary on}

Dense array EEG source estimation in neocortical epilepsy

by Yamazaki M, Tucker DM, Terrill $M$, Fujimoto A and Yamamoto T. (2013). Front. Neurol. 4:42. doi: 10.3389/fneur.2013.00042

\section{The following sentences}

Electrical source localization was conducted at the rising phase for the $\mathrm{dEEG}$ detected spikes with a linear inverse method (LAURA) using the GeoSource 1.0 software package within the space of a 3D head model derived from the Montreal Neurological Institute's average adult MRI.

\section{should be replaced by}

Electrical source localization was conducted at the rising phase for the dEEG detected spikes with a linear inverse method (LAURA) (1) using the GeoSource 1.0 software package within the space of a $3 \mathrm{D}$ head model derived from the Montreal Neurological Institute's average adult MRI.

\section{REFERENCE}

1. De Peralta Menendez RG, Murray MM, Michel CM, Martuzzi R, Andino SLG. Electrical neuroimaging based on biophysical constraints. Neuroimage (2004) 21(2):527-39.

Received: 25 August 2013; accepted: 26 August 2013; published online: 12 September 2013.
Citation: Yamazaki M, Tucker DM, Terrill M, Fujimoto A and Yamamoto T (2013) Corrigendum: Dense array EEG source estimation in neocortical epilepsy. Front. Neurol. 4:132. doi: 10.3389/fneur.2013.00132

This article was submitted to Epilepsy, a section of the journal Frontiers in Neurology.

Copyright (๑) 2013 Yamazaki, Tucker, Terrill, Fujimoto and Yamamoto. This is an open-access article distributed under the terms of the Creative Commons Attribution License (CC BY). The use, distribution or reproduction in other forums is permitted, provided the original author(s) or licensor are credited and that the original publication in this journal is cited, in accordance with accepted academic practice. No use, distribution or reproduction is permitted which does not comply with these terms. 